\title{
Change Detection in Temperature using Remote Sensing and Satellite Data for Nainital District of Uttarakhand
}

\author{
Vaibhav Deoli* \\ Department of Civil Engineering, Dev Bhoomi Institute of Technology, \\ DBGI Dehradun - 248007, India \\ *Corresponding author
}

\section{Keywords}

LST, Landsat-8, Nainital, QGIS, Mann-Kendall test

Article Info

Accepted:

04 October 2020

Available Online:

10 November 2020

\begin{abstract}
A B S T R A C T
Land surface temperature (LST) is an important factor in many areas, such as global climate change, hydrological, geo-biophysical and urban land use / land cover. As the latest satellite launched from the Landsat family, LANDSAT-8 has opened new possibilities for understanding the events on the Earth with remote sensing. In this study, an attempted has been made to estimate land surface temperature for Nainital District of Uttarakhand, India. Nainital is a tourist place which attracts thousands of tourists every year, but now the area has been affected by global warming and increasing temperature. To estimation of LST, Landsat-8 imagery series has been used in the study from 2013 2019. LST has been calculated based on NDVI algorithm. After calculation of percentage area in different land surface temperature range, the average temperature of the studied area also determined in QGIS Software. For this purpose Plug-in of QGIS has been used. The minimum average temperature has been observed 8.1129 Kelvin in year 2016 and maximum average land surface area temperature 9.5902 Kelvin has been determined in the year 2019. In last the trend has been calculated in temperature based on linear regression method and Mann-Kendall test. Both test shows increasing trend in temperature. But based on Mann-Kendall test the trend is not significant at 1\% and 5\% level of significance. That mean the temperature in the studied period has been increased but not in sufficiency. For future studies, the tool is very helpful and should be refined with in situ measurements of LST.
\end{abstract}

\section{Introduction}

Land Surface Temperature (LST) can be defined as the temperature felt when the land surface is touched with the hands or it is the skin temperature of the ground (Kim et al., 2005; Rajeshwari and Mani, 2014). It is the temperature of the surface which can be measured when the land surface is in direct contact to the measuring instrument. As the immediate main impetus in the trading of long-wave radiation and tempestuous warmth motions at the surface-climate interface, land surface temperature (LST) is one of the most significant boundaries in the physical cycles of surface energy and water balance at neighbourhood through worldwide scales ( $\mathrm{Li}$ et al., 2013). Scene structure comprises of 
anthropogenic and common segments and their spatial example. Building materials and non-vegetative surface (exposed soil) can trap sun powered radiation in the daytime and afterward re-emanate during the evening time because of the decrease in albedo. They are one reason for the expanding land surface temperature (LST), which can likewise be the reason for the vacillation of surface energy balance (Feyissa et al., 2018; Dissanayake et al., 2019).

Landsat imagery are widely used by researcher for various studies on earth surface (Shrivastvaet al., 2009; Wang et al., 2015; Reddy et al., 2017; Deoli and Kumar, 2019). Rajendra et al., (2015) studied land cover classification is used to define LSE, which is required for the calculation of LST over Thiruvananthapuram, Capital city of the state of Kerala, India. Landsat8 TIRS and OLI bands were primarily utilized to classify land cover types and to estimate the surface thermal characteristics. The results showed that surface temperature is a function of diverse surface soil-water content and vegetation cover. Jeevalakshmi et al., (2017) estimated LST over Chittoor district, Andhra Pradesh, India, using LANDSAT 8 satellite data. The variability of retrieved LSTs has been investigated with respect to Normalized Difference Vegetation Index (NDVI) values for different land use/land cover (LU/LC) types determined from the Landsat visible and NIR channels.

The results showing difference between retrieved LST and Automatic Weather Station (AWS) data indicates that the technique works by giving an error of $\pm 3^{0} \mathrm{C}$. Salih et al., (2018) studied a proposed method for the retrieval of land surface temperature (LST) from the two thermal bands of the LANDSAT- 8 data. The studies area is AlHashimiya district, south of Babylon province, middle of Iraq. The results showed that the rivers had a higher LST which is different to the other land cover types, of less than $3.47 \mathrm{C} \circ$, and the LST different for vegetation and residential area were less than $0.4 \mathrm{C} \circ$ with correlation coefficient of the two bands 10 and 11 Rbnad $10=0.70$, Rband $11=$ 0.89 respectively. Based on the above review of literatures this study has been carried out to detect change in LST for Nainital District of Uttarakhand from 2013 to 2019 using Landsat-8 OLI data and to analysis the LST trend using parametric and non-parametric test.

\section{Materials and Methods}

\section{Landsat 8 Data}

Landsat 8 (Table 1) is one of the Landsat series of NASA. The data of Landsat 8 is available in Earth Explorer website at free of cost. In the present study, the TIR bands 10 and 11 were used to estimate brightness temperature and OLI spectral bands 2, 3, 4 and 5 were used to generate NDVI of the study area. Landsat 8 provides metadata of the bands such as thermal constant, rescaling factor value etc., which can be used for calculating various algorithms like LST.

\section{Study Area}

Nainital District, a diversified physio-climatic region, lies between $29^{\circ} 35^{\prime}$ and $29^{\circ} 0^{\prime} \mathrm{N}$ latitudes and $79^{\circ} 15^{\prime}$, and $80^{\circ} 0^{\prime}$ 'E longitudes in the southern part of Kumaun division of Uttarakhand with an average elevation of 2084 meters above mean sea level (Fig. 1). The region extends over a geographical area of $3025 \mathrm{~km}^{2}$. It is bordered by Almora and Pithoragarh. Districts to the north and Udham Singh Nagar are the bordering district in the south.

The slopes of the nearby mountains are most populated, with an elevation ranging from 
1,940-2,100 m. The highest point nearby is the Naina Peak or China Peak, with an elevation of $2,619 \mathrm{~m}$. Nainital experiences subtropical highland climate according to Köppen-Geiger climate classification system. The hottest month is July with temperature ranging from $16.4{ }^{\circ} \mathrm{C}$ to $30.5{ }^{\circ} \mathrm{C}$ while the coldest month is January with temperature ranging from $1.7{ }^{\circ} \mathrm{C}\left(35.1{ }^{\circ} \mathrm{F}\right)$ to $10.7{ }^{\circ} \mathrm{C}$ $\left(51.3^{\circ} \mathrm{F}\right)$.

\section{Determination of LST}

The Land Surface Temperature can be estimated or calculated using the Landsat 8 thermal bands. It simply requires applying a set of equations through a raster image calculator (ArcMap, ArcGIS Pro, QGIS).

To calculate the LST, use the USGS formulas

Calculation of TOA (Top of Atmospheric) spectral radiance.

$\mathrm{TOA}(\mathrm{L})=\mathrm{ML} * \mathrm{Qcal}+\mathrm{AL}(4.1)$

where:

ML = Band-specific multiplicative rescaling factor from the metadata (RADIANCE MULT BAND $\mathrm{x}$, where $\mathrm{x}$ is the band number).

Qcal = corresponds to band 10 .

$\mathrm{AL}=$ Band-specific additive rescaling factor from the metadata (RADIANCE ADD BAND $\mathrm{x}$, where $\mathrm{x}$ is the band number).

$\mathrm{TOA}=0.0003342 *$ “Band 10" $+0.1(4.2)$

Therefore the equation must be solved using the Raster Calculator tool in ArcMap.

TOA to Brightness Temperature conversion
$\mathrm{BT}=(\mathrm{K} 2 /(\ln (\mathrm{K} 1 / \mathrm{L})+1))-273.15(4.3)$

where

$\mathrm{K} 1=$ Band-specific thermal conversion constant from the metadata (K1 CONSTANT BAND $\mathrm{x}$, where $\mathrm{x}$ is the thermal band number).

$\mathrm{K} 2=$ Band-specific thermal conversion constant from the metadata (K2 CONSTANT BAND $\mathrm{x}$, where $\mathrm{x}$ is the thermal band number).

$\mathrm{L}=\mathrm{TOA}$

Therefore, to obtain the results in Celsius, the radiant temp.is adjusted by adding 14 the absolute zero (approx. $-273.15^{\circ} \mathrm{C}$ ).

$\mathrm{BT}=(1321.0789 / \mathrm{Ln}((774.8853 /$ "\% TOA $\% ")+1))-273.15(4.4)$

Calculate the NDVI (Normalized Difference Vegetation Index)

$\mathrm{NDVI}=($ Band $5-$ Band 4$) /($ Band $5+$ Band 4) (4.5)

Note that the calculation of the NDVI is important because, subsequently, the proportion of vegetation $(\mathrm{Pv})$, which is highly related to the NDVI, and emissivity $(\varepsilon)$, which is related to the $\mathrm{Pv}$, must be calculated.

NDVI $=$ Float $($ Band $5-$ Band 4) $/$ Float (Band $5+$ Band 4) (4.6)

Calculate the proportion of vegetation $\mathrm{Pv}$

$\mathrm{Pv}=$ Square $[($ NDVI - NDVImin $) /$

(NDVImax - NDVImin)] (4.7)

Usually the minimum and maximum values of the NDVI image can be displayed directly in the image (both in ArcGIS, QGIS, ENVI, 
Erdas Imagine), otherwise you must open the properties of the raster to get those values.

$\mathrm{P}_{\mathrm{v}}=$ Square (("NDVI" $\quad$ - 0.216901) / $(0.632267-0.216901))(4.8)$

Calculate Emissivity $\varepsilon$

$\varepsilon=0.004 * \mathrm{P}_{\mathrm{v}}+0.986(4.9)$

Simply apply the formula in the raster calculator; the value of 0.986 corresponds to a correction value of the equation.

Calculate the Land Surface Temperature

$\mathrm{LST}=(\mathrm{BT} /(1+(0.00115 * \mathrm{BT} / 1.4388) *$ $\operatorname{Ln}(\varepsilon)))(4.10)$

Finally apply the LST equation to obtain the surface temperature map. As a result of the process developed, there is a map of the Land Surface Temperature, it should be noted that it is not equal to the air temperature.

\section{Trend analysis in LST}

\section{Linear regression}

Linear regression is a parametric test and used for predictive analysis of data. Regression analysis is considered with time as the independent variable and rainfall as the dependent variable.

A linear regression equation is presented as $y$ $=\mathrm{nx}+\mathrm{k}$ where $\mathrm{x}$ is the independent variable, $\mathrm{y}$ is the dependent variable on $\mathrm{x}, \mathrm{n}$ is the slope of the line fitted by the trend in data and $\mathrm{k}$ is a constant used in the equation. Linear regression assumed normal distribution in data.

\section{Mann- Kendall test}

Mann- Kendall test is a non-parametric test used to determined trend in long term series data to check data follow either positive trend or negative trend or no trend.

It is the rank based test for determining statistically trends in a time series data and is not affected by outliers. In the Mann Kendall test, a time series $\mathrm{x}$ was ranked from $\mathrm{p}=\mathrm{p} 1,2$,

$\mathrm{n}-1$ and another time series $\mathrm{x}$ from $\mathrm{q}=2,3, \mathrm{n}$, $\mathrm{q}$ where $\mathrm{n}$ is the number of data points.

Each data point in $\mathrm{x}_{\mathrm{p}}$ was then used as a reference point and compared with all other data points in $x(q>p)$, to obtain the values of the sign $q$ for each comparison using following equation.

The Mann - Kendal's statistic $S$ is calculated using following equation

$\sum_{p=1}^{n-1} \sum_{q=p+1}^{n} \operatorname{sgn}\left(x_{q q}-x_{p p}\right)$

where $\mathrm{n}$ is the number of observed data point. For $n=10$, the Mann- Kendal's statistic $S$ is approximately normally distributed with zero mean (Mann 1945, Kendall 1975). The variance of $\mathrm{S}$ is calculated as

$\operatorname{Var}(S)=\frac{n(n-1)(2 n-5) \sum_{i=1}^{m} t(p)(p-1)(2 p-5)}{18}$

where, $m$ is the number of tied groups (a tied group is a set of sample data having the same value) and tips the number of data points in the $\mathrm{p}^{\text {th }}$ tied group.

The test statistic $\mathrm{Z}$ is commuted as

$$
\mathrm{Z}=\left\{\begin{array}{l}
\frac{\mathrm{S}-1}{\sqrt{\operatorname{var}(\mathrm{S})}} \text { if } S>0 \\
0 \\
\frac{S-1}{\sqrt{\operatorname{var}(S)}} \text { if } S<0
\end{array}\right.
$$




\section{Results and Discussion}

\section{NDVI analysis}

In this study, the minimum value of NDVI is fixed at -0.5 which may be because of the lakes in Nainital District which shows always a fix value. The upper limit of the NDVI is varying as 0.6711 in year 2013 to 0.6814 in year 2018. The average value of NDVI for every year has been shown in Table 2. Based on the average values of NDVI, scatter plot has been plotted as shown in Figure 2 . Furthermore, a trend line has been drawn which shows an increasing trend in that area for studied period. Increase in trend shows that the increase in built-up area or decreasing in water-cover area or both.

The calculated NDVI values further used to determine the land surface temperature and changes in temperature from year 2013 to 2019.

\section{Land surface temperature analysis}

For the purpose of land surface temperature mapping, NDVI has been used. Landsat -8 imageries analysed in QGIS software and to analysed temperature and then further percentage area has in different temperature range has been determined. To detect the land surface temperature variation, every year one image has been used.

The image is taken in the month of October. The range of temperature is divided as 10 Kelvin gap between each range whereas the minimum range has been decided as less than 273 Kelvin and maximum range has been decided as more than 303 Kelvin. The intermediate ranges are 273 to 283 Kelvin, 283 to 293 Kelvin and 293 to 303 Kelvin. The percentage of area between these ranges has been calculated for each year.

\section{Land surface temperature in year 2013}

Table 3 shows the percentage of area in different range. In 2013 the maximum area was between temperature range $273-283$ Kelvin and minimum area was between temperature range $>303$ Kelvin. $43.53 \%$ of total district area was in 273-283 Kelvin temperature range followed by $25.33 \%$ area in $283-293$ Kelvin. $21.25 \%$ of area determined in the temperature range of $<273$ Kelvin, $9.43 \%$ of area determined in the $293-303$ Kelvin and minimum area of $0.46 \%$ area was in the temperature >303 Kelvin.

\section{Land surface temperature in year 2014}

Table 3 shows the percentage of area in different range. In 2014 the maximum area of $43.15 \%$ was between temperature range 273 283 Kelvin and minimum area of $0.34 \%$ was between temperature range $>303$ Kelvin. $22.13 \%$ area was determined between temperature ranges of < 273 Kelvin, $24.27 \%$ area was between 283-293 Kelvin and 9.75\% area determined in the range of $293-303$ Kelvin.

\section{Land surface temperature in year 2015}

Table 3 shows the percentage of area in different range. In year 2015, the maximum area of studied district also was in the same range of $273-283$ Kelvin. $44.21 \%$ of total area was in this range followed by $23.33 \%$ of area was in the $283-293$ Kelvin temperature range. $21.13 \%$ of the area was in the range < 273 Kelvin, $11 \%$ of area was in 293 to 33 Kelvin and minimum area of $0.33 \%$ has temperature more than 303 Kelvin.

\section{Land surface temperature in year 2016}

Table 3 shows the percentage of area in different range. In 2016 the maximum area was between temperature range $273-283$ 
Kelvin and minimum area was between temperature range $>303$ Kelvin. $46.92 \%$ of total district area was in 273-283 Kelvin temperature range followed by $24.39 \%$ area in $<273$ Kelvin. $22.64 \%$ of area determined in the temperature range of $283-293$ Kelvin, $5.91 \%$ of area determined in the $293-303$ Kelvin and minimum area of $0.14 \%$ area was in the temperature $>303$ Kelvin.

Table.1 Specification of Landsat-8 imagery

\begin{tabular}{|c|c|c|c|}
\hline Band & Description & $\begin{array}{c}\text { Wavelength } \\
\text { (micro meters) }\end{array}$ & $\begin{array}{c}\text { Resolution } \\
\text { (meters) }\end{array}$ \\
\hline B1 & Violet-Deep Blue & $0.43-0.45$ & 30 \\
\hline B2 & Blue & $0.45-0.51$ & 30 \\
\hline B3 & Green & $0.53-0.59$ & 30 \\
\hline B4 & Red & $0.64-0.67$ & 30 \\
\hline B5 & Near Infrared & $0.85-0.88$ & 30 \\
\hline B6 & Shortwave Infrared & $1.57-1.65$ & 30 \\
\hline B7 & Shortwave Infrared & $2.11-2.29$ & 30 \\
\hline B8 & Panchromatic & $0.50-0.68$ & 15 \\
\hline B9 & Cirrus Clouds & $1.36-1.38$ & 30 \\
\hline B10 & Thermal Infrared & $10.62-11.19$ & 100 \\
\hline B11 & Thermal Infrared & $11.50-12.51$ & 100 \\
\hline
\end{tabular}

Table.2 NDVI values based on Landsat -8 for every studied year

\begin{tabular}{|c|c|c|}
\hline Year & NDVI Range & Average value of NDVI \\
\hline $\mathbf{2 0 1 3}$ & -0.5 to 0.6711 & 0.08555 \\
\hline $\mathbf{2 0 1 4}$ & -0.5 to 0.6721 & 0.08605 \\
\hline $\mathbf{2 0 1 5}$ & -0.5 to 0.6777 & 0.08885 \\
\hline $\mathbf{2 0 1 6}$ & -0.5 to 0.6801 & 0.09005 \\
\hline $\mathbf{2 0 1 7}$ & -0.5 to 0.6729 & 0.08645 \\
\hline $\mathbf{2 0 1 8}$ & -0.5 to 0.6814 & 0.09070 \\
\hline $\mathbf{2 0 1 9}$ & -0.5 to 0.6811 & 0.09055 \\
\hline
\end{tabular}

Table.3 Percentage studied area in different temperature range for year 2013-2019

\begin{tabular}{|c|c|c|c|c|c|c|c|}
\hline \multirow{2}{*}{$\begin{array}{c}\text { Temperature Range } \\
\text { (Kelvin) }\end{array}$} & \multicolumn{7}{|c|}{ Percentage Area in that Range(\%) } \\
\hline$<\mathbf{2 7 3}$ & $\mathbf{2 0 1 3}$ & $\mathbf{2 0 1 4}$ & $\mathbf{2 0 1 5}$ & $\mathbf{2 0 1 6}$ & $\mathbf{2 0 1 7}$ & $\mathbf{2 0 1 8}$ & $\mathbf{2 0 1 9}$ \\
\hline $\mathbf{2 7 3 - 2 8 3}$ & $41.25 \%$ & $22.13 \%$ & $21.13 \%$ & $24.39 \%$ & $18.45 \%$ & $20.25 \%$ & $20.91 \%$ \\
\hline $\mathbf{2 8 3 - 2 9 3}$ & $25.53 \%$ & $43.51 \%$ & $44.21 \%$ & $46.92 \%$ & $49.1 \%$ & $41.88 \%$ & $42.55 \%$ \\
\hline $\mathbf{2 9 3 - 3 0 3}$ & $9.33 \%$ & $24.27 \%$ & $23.33 \%$ & $22.64 \%$ & $21.25 \%$ & $26.03 \%$ & $27.56 \%$ \\
\hline $\mathbf{3 0 3}$ & $0.46 \%$ & $9.75 \%$ & $11.00 \%$ & $5.91 \%$ & $10.69 \%$ & $11.29 \%$ & $8.45 \%$ \\
\hline
\end{tabular}


Table.4 Average LST values in different years

\begin{tabular}{|c|c|}
\hline Year & Average LST (Kelvin) \\
\hline $\mathbf{2 0 1 3}$ & 8.8447 \\
\hline $\mathbf{2 0 1 4}$ & 9.0765 \\
\hline $\mathbf{2 0 1 5}$ & 9.1324 \\
\hline $\mathbf{2 0 1 6}$ & 8.1129 \\
\hline $\mathbf{2 0 1 7}$ & 9.2476 \\
\hline $\mathbf{2 0 1 8}$ & 9.5548 \\
\hline $\mathbf{2 0 1 9}$ & 9.5902 \\
\hline
\end{tabular}

Fig.1 Location map of Nainital District

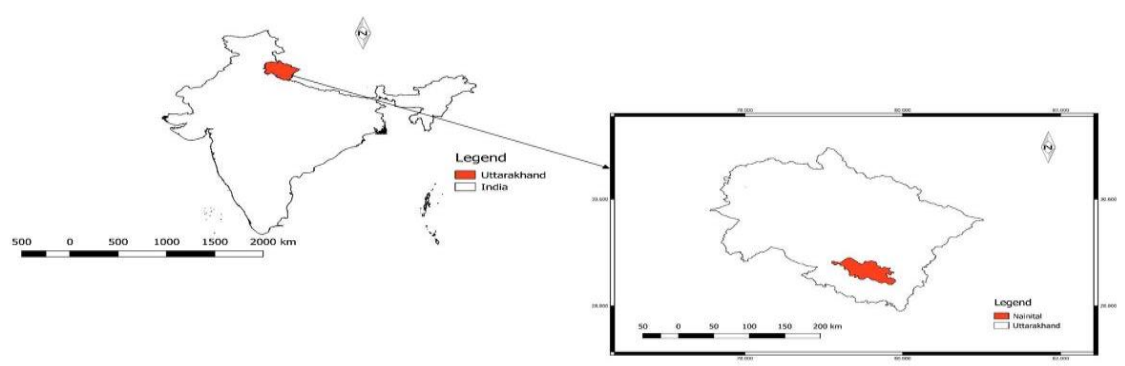

Fig.2 Linear trend in NDVI value based on linear regression

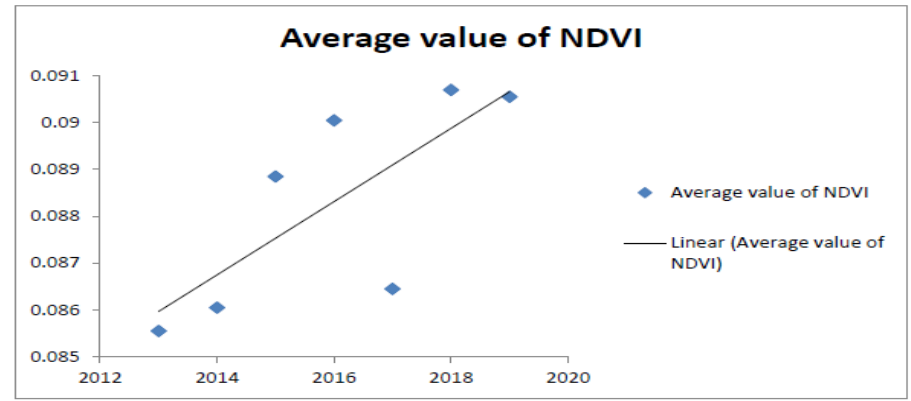

Fig.3 Trend in average LST using Linear Regression

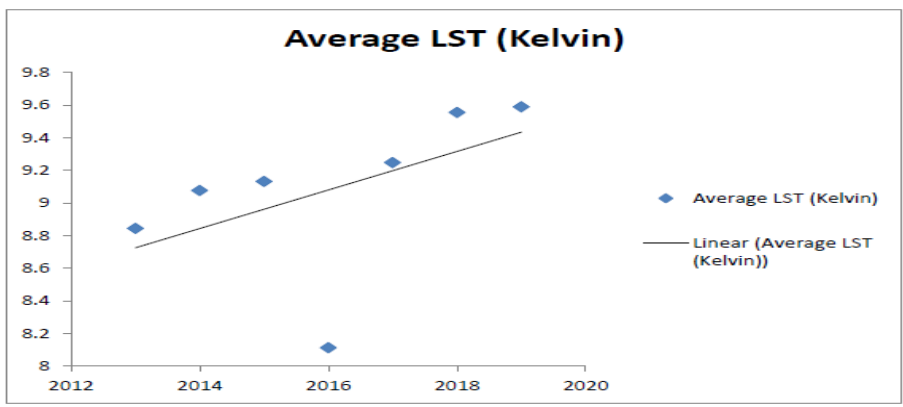




\section{Land surface temperature in year 2017}

Table 3 shows the percentage of area in different range. In year 2017, the maximum area of studied district also was in the same range of $273-283$ Kelvin. $49.1 \%$ of total area was in this range followed by $21.25 \%$ of area was in the $283-293$ Kelvin temperature range. $18.45 \%$ of the area was in the range < 273 Kelvin, $10.69 \%$ of area was in 293 to 33 Kelvin and minimum area of $0.51 \%$ has temperature more than 303 Kelvin.

\section{Land surface temperature in year 2018}

Table 3 shows the percentage of area in different range. In 2018 the maximum area of $41.88 \%$ was between temperature range $273-$ 283 Kelvin and minimum area of $0.55 \%$ was between temperature range $>303$ Kelvin. $2.25 \%$ area was determined between temperature ranges of < 273 Kelvin, $26.03 \%$ area was between 283-293 Kelvin and $11.29 \%$ area determined in the range of $293-$ 303 Kelvin.

\section{Land surface temperature in year 2019}

Table 3 shows the percentage of area in different range. In 2019 the maximum area was between temperature range $273-283$ Kelvin and minimum area was between temperature range $>303$ Kelvin. $42.55 \%$ of total district area was in 273-283 Kelvin temperature range followed by $27.56 \%$ area in $283-293$ Kelvin. $20.91 \%$ of area determined in the temperature range of <273 Kelvin, $8.45 \%$ of area determined in the $293-303$ Kelvin and minimum area of $0.53 \%$ area was in the temperature >303 Kelvin.

\section{Average temperature analysis}

After calculation of percentage area in different land surface temperature range, the average temperature of the studied area also determined in QGIS Software. For this purpose Plug-in of QGIS has been used. The average temperature of the area has been tabulated in Table 4. The minimum average temperature has been observed 8.1129 Kelvin in year 2016 and maximum average land surface area temperature 9.5902 Kelvin has been determined in the year 2019 which is few more than temperature in 2018. In 2013, the eland surface temperature of the studied area has been determined as 8.8447 Kelvin, in 2014, average land surface temperature was 9.0765 Kelvin, in 2015 the land surface temperature was 9.1324 Kelvin, in 2017 the LST has been determined as 9.2476 Kelvin and in 2018, and the LST has been calculated as 9.5548 .

\section{Trend analysis in average temperature linear regression analysis}

Linear regression analysis has been computed to determine the trend line in the average temperature from year 2013 to 2017. The graph is shown in Figure 3. From this it is clear that the trend in average temperature has been increasing in studied period.

\section{Mann-Kendall Test}

In the study, Mann-Kendall test has been used to determine the significance of trend. For the period of study, the value of Mann-Kendall statistic i.e. $Z$ value is 0.0127 . The value of $Z$ is positive which shows an increment in temperature for studied period. For significance analysis, the value has been tested at 1\% level of significance and 5\% level of significance. The result showed that the observed value is not significant at both $1 \%$ and $5 \%$ level of significance.

In conclusions this study has been undertaken for determining land surface temperature for Nainital District of Uttarakhand, India. Land surface temperature has been directly affected 
by climate changes and green-house gases. Hence it is important to regularly measure the land surface temperature. After successfully determination of LST, for Nainital District from 2013 to 2019, trend in temperature has been determined by the linear regression and Mann-Kendall test.

The conclusions of the study are listed below:

LST of the studied area was determined based on its brightness temperature and NDVI suing SW algorithm.

The maximum average NDVI value determined in year 2018 and minimum NDVI value determined in year 2013.

The average value of NDVI has been determined in range of 0 to 0.1 which shows the maximum area was covered by vegetation. The maximum area of studied district has been in the temperature range of $273-283$ Kelvin.

The minimum area of studied district has been in the temperature range of $<303$ Kelvin.

The minimum average temperature has been observed 8.1129 Kelvin in year 2016 and maximum average land surface area temperature 9.5548 Kelvin has been determined in the year 2019.

Trend in land surface temperature based on liner regression method as well as by MannKendall test show increasing trend in temperature.

The $\mathrm{z}$-value is not significant at $1 \%$ and $5 \%$ level of significance which shows the land surface temperature increment is not significant.

\section{References}

Deoli, V., and Kumar, D. (2019).Remote Sensing and GIS Approach for Spatiotemporal Mapping of Ramganga Reservoir. Int.J.Curr.Microbiol.App.Sci. 8(05): 775-783.

Dissanayake, D. M. S. L. B., Morimoto, T.,
Murayama, Y., \&Ranagalage, M. (2019). Impact of landscape structure on the variation of land surface temperature in sub-saharan region: $\mathrm{A}$ case study of Addis Ababa using Landsat data (19862016). Sustainability, 11(8), 2257.

Feyissa, G., Gebremariam, E. (2018). Mapping of landscape structure and forest cover change detection in the mountain chains around Addis Ababa: The case of Wechecha Mountain, Ethiopia. Remote Sens. Appl. Soc. Environ. 11: 254-264.

Jeevalakshmi, D., Reddy, S. N., and Manikiam B. (2017).Land cover classification based on NDVI using LANDSAT8 time series: a case study Tirupati region. International Conference on Communication and Signal Processing ICCSP, Pp. 13321335.

Kim, H. M., Kim, B. K., and You, K. S. (2005). A statistic correlation analysis algorithm between land surface temperature and vegetation index. JIPS, 1(1), 102-106.

Li, Z. L., Tang, B. H., Wu, H., Ren, H., Yan, G., Wan, Z., and Sobrino, J. A. (2013). Satellite-derived land surface temperature: Current status and perspectives. Remote sensing of environment, 131: 14-37.

RajendranP, and Mani K. (2015). Estimation of spatial variability of land surface temperature using Landsat 8 imagery. International Journal of Engineering and Science 11(4): 19-23.

Rajeshwari, A., and Mani, N. D. (2014). Estimation of land surface temperature of Dindigul district using Landsat 8 data. International Journal of Research in Engineering and Technology, 3(5): 122-126.

Reddy, S. N., and Manikiam, B. (2017).Land surface temperature retrieval from 
LANDSAT data using emissivity estimation. International Journal of Applied Engineering Research, 12(20): 9679-9687.

Salih M. M, Jasim, O. Z., Hassoon, K. I, and Abdalkadhum A. J. (2018). Land Surface Temperature Retrieval from LANDSAT-8 Thermal Infrared Sensor Data and Validation with Infrared Thermometer Camera". International Journal of Engineering \& Technology 7(4):608-612.

Srivastava, P. K., Majumdar, T. J., and
Bhattacharya, A. K. (2009).Surface temperature estimation in Singhbhum Shear Zone of India using Landsat-7 $\mathrm{ETM}+$ thermal infrared data. Advances in space research, 43(10): 1563-1574. Wang, F., Qin, Z., Song, C., Tu, L., Karnieli, A., and Zhao, S. (2015). An improved mono-window algorithm for land surface temperature retrieval from Landsat 8 thermal infrared sensor data. Remote sensing, 7(4), 4268-4289.

How to cite this article:

Vaibhav Deoli. 2020. Change Detection in Temperature using Remote Sensing and Satellite Data for Nainital District of Uttarakhand. Int.J.Curr.Microbiol.App.Sci. 9(11): 420-429. doi: https://doi.org/10.20546/ijcmas.2020.911.051 